\title{
Changes in cigarette consumption, prices, and tobacco industry revenues associated with California's Proposition 99
}

\author{
Stanton A Glantz
}

\begin{abstract}
Objective - To assess changes in tobacco consumption, pricing, and industry revenues associated with enactment of California's Proposition 99 tax increase on tobacco.
\end{abstract}

Design-Regression analysis of reported annual consumption, pricing and tax data as a function of calendar year, including dummy variables to model the effects of Proposition 99.

Subjects-People in California and the US.

Results - EnactmentofCalifornia'sProposition 99 was associated with a tripling (from 46 million packs/year to 164 million packs/year; $p<0.001$ ) of the rate at which cigarette consumption was falling in California. These effects were not observed in the rest of the US. Proposition 99 reduced total cigarette consumption from implementation on 1 January 1989 to 30 June 1992 by approximately 802 million packs of cigarettes, worth $\$ 1.1$ billion in pre-tax sales and approximately \$286 million in profits to the tobacco industry. The tobacco industry was, however, able to maintain increasing revenues because of increased pre-tax prices. The effect of Proposition 99 on tobacco consumption in California significantly slowed in 1992 (to 19 million packs/year; $p<0.007$ ), concurrently with suspension of the large anti-smoking media campaign funded by Proposition 99.

Conclusion - The combined effects of the price increase and anti-smoking campaign had a major effect on tobacco consumption in California.

(Tobacco Control 1993; 2 : 311-4)

Department of

Medicine, Institute for Health Policy Studies,

University of

California, San

Francisco, CA 94143,

USA

S A Glantz

Correspondence to:

S A Glantz, Professor of

Medicine, Division of

Cardiology, Box 0124,

University of California,

University of California,

0124, USA

\section{Introduction}

In 1988, the people of California enacted Proposition 99, which increased the tax on cigarettes by 25 cents per pack and allocated $20 \%$ of the resulting revenues to a Health Education Account for school- and community-based tobacco prevention and cessation. ${ }^{1}$ The combined effects of the increase in price associated with the tax, together with the large tobacco education programme funded by the Health Education Account, led to a decline in tobacco consumption following implemen- tation of Proposition 99. ${ }^{2-6}$ It will probably require several years to accumulate enough data to determine a detailed demand function for cigarettes that quantifies the relative impacts of price changes, the anti-tobacco campaign funded by Proposition 99, and changes in tobacco advertising practices. This paper uses data published by the US Tobacco Institute ${ }^{7}$ on tobacco taxation and consumption to assess the impact of Proposition 99 on tobacco sales, prices and company revenues.

\section{Methods}

Data on annual cigarette sales, tax rates, per capita cigarette consumption, and price were obtained from the US Tobacco Institute ${ }^{7}$ for the state of California and the US for the period from 1980 to 1992 . These data are published by fiscal year, 1 July to 30 June (because the data are presented by fiscal year, a point plotted for 1992 reflects data for 1 July 1991 to 30 June 1992). Per capita values are based on the entire "consumer" population, estimated by the Tobacco Institute. The Tobacco Institute average prices include generic cigarettes beginning in 1990, when they began comprising an important component of the cigarette market. (In 1990 generics only accounted for about $1.5 \%$ of the average prices of cigarettes; by 1992 they accounted for about $10 \%$ of the average price.) Prices were analysed in both current dollars and constant 1992 dollars, obtained by deflating current dollars by the consumer price index.

From 1981 to 88 (before Proposition 99 went into force), the relationships between the variables of interest and time were linear, so this period was taken as the baseline for establishing historical trends. The following regression equation was used to model the effects of Proposition 99:

$$
y=b_{1980}+b_{t} t+b_{99}(t-1988.5) D_{99}+b_{1992} D_{1992}
$$

where $\mathrm{y}$ is the dependent variable of interest (ie, per capita cigarette consumption, price, or tobacco company revenues), $t$ is time (year), $D_{99}$ is a dummy variable ${ }^{8}$ set to 1 if $t \geqslant 1989$ and 0 otherwise, which is used to test for a change in the slope of the regression line following implementation of Proposition 99, and $D_{1992}$ equals 1 for $t=1992$ and 0 otherwise, which is used to test for an additional slope change in 1992 . The value 1988.5 is subtracted from the year because Proposition 99 went into 
force 1 January 1989, which is half-way through the 1989 fiscal year (1 July 1988 to 30 June 1989); $b_{t}$ quantifies the annual change in y prior to enactment of Proposition 99 and $b_{99}$ quantifies the change in this annual rate associated with implementation of Proposition 99. A significant value of $b_{99}$ indicates a significant change in the rate of change of $y$ associated with Proposition 99. Hence, if tobacco consumption in California continued to fall along the pre-Proposition 99 historical trend, there would be no change in slope and $\mathrm{b}_{99}$ would be zero. Likewise, a significant value of $b_{1992}$ indicates that the 1992 value falls off the trend established following Proposition 99.

Regression coefficients are reported \pm standard error. A value of $p<0.05$ was considered statistically significant. All computations were done with Minitab Version 8.2.

\section{Results}

Figure 1 confirms earlier reports ${ }^{2-4,6}$ that Proposition 99 was associated with a significant acceleration of the historical decline in cigarette consumption in California. From 1981 to 1988, cigarette consumption in California was falling by 45.9 million packs/year $(\mathrm{p}<0.001)$, about $2 \%$ per year (see table). After enactment of Proposition 99, the rate of decline more than tripled, to 164.3 million packs /year $(\mathrm{p}<0.001$;

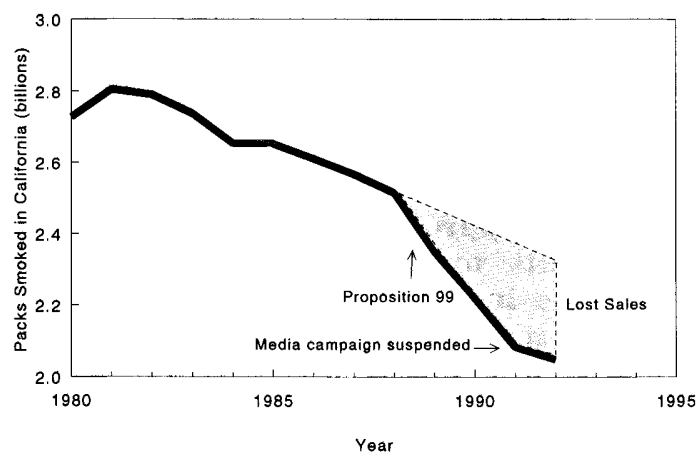

Figure 1 Total cigarette consumption in California before and after passage of Proposition 99. Consumption, which had been falling in California prior to passage of Proposition 99, fell even faster after Proposition 99's enactment. This decline slowed significantly in 1992, concurrently with suspension of the Proposition 99-funded anti-smoking media campaign.
$-164.3=-45.9-118.4$ from table). In 1992, this decline greatly decelerated, to 19.4 million packs $/$ year $\quad(p=0.007 ; \quad-19.4=-45.9$ $-118.4+144.9$ from table). In 1992, cigarette consumption was falling more slowly than before passage of Proposition 99.

Analysis of per capita consumption data permits comparison of California data with the US as whole. The historical rate of decline in per capita consumption in California, which had been falling approximately in parallel with national changes $(-4.0 \pm 0.2$ packs/person/ year for California vs $-3.8 \pm 0.3$ packs/ person/year for the US as a whole; see table) significantly accelerated following enactment of Proposition 99 (figure 2). Prior to enactment of Proposition 99, per capita cigarette consumption in California had been falling at -4.0 packs/year $(p<0.001)$. With enactment of Proposition 99, this rate double, to -8.0 packs/year $\quad(\mathrm{p}<0.001 ; \quad-8.0=-4.0-4.0$ from table). In 1992, the rate at which per capita cigarette consumption in California had been declining significantly decelerated, to -1.4 packs $/$ year $(\mathrm{p}=0.032 ;-1.4=$ $-4.0-4.0+6.6$ from table). In 1992, per capita cigarette consumption in California was falling more slowly than before passage of Proposition 99.

Analysis of national per capita consumption data, which may appear in figure 2 to be similar

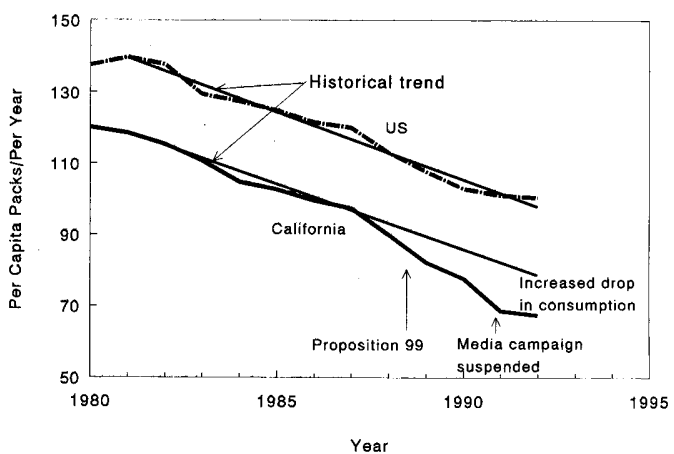

Figure 2 Per capita tobacco consumption in California and the US before and after passage of Proposition 99. California consumption was falling in parallel to the US as a whole before Proposition 99, accelerated following its enactment, then decelerated significantly in 1992.

Table Results of multiple regression analyses

\begin{tabular}{|c|c|c|c|c|c|}
\hline Dependent variable & $b_{1980}$ & $b_{t}\left(\right.$ year $\left.^{-1}\right)$ & $b_{99}\left(\right.$ year $\left.^{-1}\right)$ & $b_{1992}\left(y_{e a r}^{-1}\right)$ & $R^{2}$ \\
\hline $\begin{array}{l}\text { California tobacco consumption } \\
\text { (millions of packs of cigarettes) }\end{array}$ & $\begin{array}{r}2869 \pm 19 \\
(0.001)\end{array}$ & $\begin{array}{c}-45.9 \pm 3.5 \\
(0.001)\end{array}$ & $\begin{array}{c}-118.4 \pm 13.8 \\
(0.001)\end{array}$ & $\begin{array}{l}144.9 \pm 40.6 \\
(0.007)\end{array}$ & 0.994 \\
\hline $\begin{array}{l}\text { California per capita cigarette consumption } \\
\text { (packs/year/person) }\end{array}$ & $\begin{array}{l}122.8 \pm 1.2 \\
(0.001)\end{array}$ & $\begin{array}{c}-4.0 \pm 0.2 \\
(0.001)\end{array}$ & $\begin{array}{c}-4.0 \pm 0.9 \\
(0.001)\end{array}$ & $\begin{array}{c}6.6 \pm 2.6 \\
(0.032)\end{array}$ & 0.992 \\
\hline $\begin{array}{l}\text { US per capita cigarette consumption } \\
\text { (packs/year/person) }\end{array}$ & $\begin{array}{l}143.5 \pm 1.4 \\
(0.001)\end{array}$ & $\begin{array}{l}-3.8 \pm 0.3 \\
(0.001)\end{array}$ & $\begin{array}{l}-0.9 \pm 1.0 \\
(0.390)\end{array}$ & $\begin{array}{l}5.2 \pm 3.0 \\
(0.123)\end{array}$ & 0.982 \\
\hline $\begin{array}{l}\text { California price } \\
\text { (current } \$ / \text { pack) }\end{array}$ & $\begin{array}{l}0.631 \pm 0.032 \\
\quad(0.001)\end{array}$ & $\begin{array}{l}0.065 \pm 0.006 \\
(0.001)\end{array}$ & $\begin{array}{l}0.212 \pm 0.023 \\
(0.001)\end{array}$ & $\begin{array}{l}0.004 \pm 0.070 \\
(0.488)\end{array}$ & 0.978 \\
\hline $\begin{array}{l}\text { California price } \\
\text { (constant } 1992 \$ / \text { pack) }\end{array}$ & $\begin{array}{l}0.993 \pm 0.039 \\
(0.001)\end{array}$ & $\begin{array}{l}0.045 \pm 0.007 \\
(0.001)\end{array}$ & $\begin{array}{l}0.163 \pm 0.028 \\
(0.001)\end{array}$ & $\begin{array}{l}0.061 \pm 0.084 \\
(0.488)\end{array}$ & 0.978 \\
\hline $\begin{array}{l}\text { California pre-tax price } \\
\text { (current } \$ / \text { pack) }\end{array}$ & $\begin{array}{l}0.458 \pm 0.026 \\
(0.001)\end{array}$ & $\begin{array}{l}0.053 \pm 0.005 \\
(0.001)\end{array}$ & $\begin{array}{l}0.117 \pm 0.019 \\
(0.001)\end{array}$ & $\begin{array}{l}0.102 \pm 0.057 \\
(0.107)\end{array}$ & 0.989 \\
\hline $\begin{array}{l}\text { Tobacco industry gross revenues in California } \\
\text { (millions of current } \$ \text { ) }\end{array}$ & $\begin{array}{r}1348 \pm 68 \\
(0.001)\end{array}$ & $\begin{array}{r}111 \pm 13 \\
(0.001)\end{array}$ & $\begin{array}{l}87 \pm 50 \\
(0.122)\end{array}$ & $\begin{array}{l}320 \pm 148 \\
(0.062)\end{array}$ & 0.972 \\
\hline
\end{tabular}

Notes: Values following \pm are standard errors; numbers in parentheses are p-values testing the null hypotheses that the regression coefficients are zero. $\mathrm{n}=12$ data points for all regressions. 
to the California data, did not reveal any significant effects of Proposition $99 ; b_{99}$ and $\mathrm{b}_{1992}$ were not significantly different from zero (table) because the national changes were smaller than the changes in California.

The increase in the rate of decline in cigarette consumption that followed Proposition 99 meant that 802 million fewer packs of cigarettes were consumed in California than would be expected based on historical trends established before Proposition 99 went into effect (figure 1). This estimate was obtained by summing the differences in the projected tobacco consumption estimated by extrapolating the linear trend established between 1981 and 1988, and adding up the differences between the predicted consumption and the actual consumption. (This difference is the shaded area in figure 1.) Multiplying these lost sales with the actual pre-tax price (ie, retail price less federal and state taxes) of the cigarettes yields the estimate that these cigarettes were worth $\$ 1.1$ billion in pre-tax sales lost to the tobacco industry.

The tobacco industry's accelerating pre-tax price increases during the late 1980 s in California mirrored similar changes nationally, and these increases compensated for these lost revenues, both in current dollars and constant dollars. Between 1981 and 1988, pre-tax California cigarette prices increased by 5.3 cents/pack/year in current dollars $(\mathrm{p}<0.001$; see table). The tobacco industry more than tripled the rate of pre-tax price increase, to 17.1 cents/pack/year in current dollars following Proposition 99 ( $\mathrm{p}<0.001 ; \$ 0.071=$ $\$ 0.053+\$ 0.117)$. By 1992, a greater fraction of the cost increase in a pack of cigarettes was due to pre-tax price increases by the tobacco industry than the 25 cent tax increase imposed by Proposition 99. As a result, the fraction of the retail price due to the tax is continuing to fall, despite passage of Proposition 99.

Likewise, in constant 1992 dollars, the tobacco industry had been increasing pre-tax prices at 4.5 cents/pack/year prior to passage of Proposition 99 and at 22.4 cents/pack/year beginning in the 1990 fiscal year. The price increase associated with the new tax combined with the increase in tobacco industry prices significantly accelerated the rate at which retail cigarette prices were increasing following passage of Proposition 99, in both current and constant dollar terms (table). This pattern did not change significantly in 1992 (ie, $b_{1992}$ is not significant for either price variable; table). The industry's price increases more than offset the reduction in sales, so that tobacco industry revenues from cigarette sales in California continued to rise, despite Proposition 99 (table).

\section{Discussion}

Proposition 99 and its Health Education Account have had a dramatic effect on cigarette consumption in California. During the 3.5 years ending 30 June 1992, cigarette consumption was 802 million packs of cigarettes below what would have been expected from historical trends, resulting in lost revenues to the tobacco industry of $\$ 1.1$ billion. Given a $26 \%$ profit margin on cigarette sales, ${ }^{9}$ and assuming that profit is strictly proportional to sales, this loss translates into a reduction in profits of $\$ 286$ million for the tobacco industry.

The changes in tobacco consumption following Proposition 99 were probably the result of several factors. There is a negative price elasticity for tobacco, ${ }^{10}$ so some of the drop is probably due to price increases from the tax increase and manufacturers' wholesale price increases. The price effect of the tax, however, appears to have been transient ${ }^{2,6}$ and had significantly dissipated by 1990 .

The most visible component of Proposition 99's Health Education campaign was the large anti-tobacco media campaign. Previous research $^{11-13}$ has documented the effectiveness of anti-tobacco media messages in discouraging smoking. The first wave of the Proposition 99 media campaign cost $\$ 28$ million and ran between April 1990 and September 1991. The campaign was to resume at $\$ 16$ million per year in late 1991, but was cancelled by Governor Pete Wilson and then Director of Health Services, Molly Coye. (The American Lung Association of California sued Wilson and Coye and obtained a court order reinstating the media campaign, ${ }^{14,15}$ but it had not reappeared as of 30 June 1992, the end of the period of this study.) Using an analysis of month-to-month tobacco excise tax data, the California Department of Health Services ${ }^{6}$ estimated that tobacco consumption in California started falling in September 1988, the same time that the Proposition 99 election campaign started in earnest, which raised the public profile of tobacco use as an issue. The Department noted that this period of decline persisted until May 1989, after which consumption began to increase. ${ }^{6}$ (The tax went into effect on 1 January 1989.) A second period of accelerated decline in consumption occurred between April 1990 and April 1991, which corresponds approximately to the time that the media campaign was visible. ${ }^{6}$ The disappearance of the media campaign early in the 1992 fiscal year may account for the sudden deceleration in the rate at which cigarette consumption was falling in California following Proposition 99 (figures 1 and 2). The national data presented in figure 2 appear to show a similar deceleration at about the same time; however, this change was not statistically significant.

The Proposition 99 Health Education Account funded a variety of other tobacco control activities, particularly local coalition building to enact controls on smoking in workplaces and public places as well as access to cigarette vending machines, and such policies appear to affect tobacco consumption. ${ }^{16}$ While smokefree workplaces do contribute significantly to reducing tobacco consumption, ${ }^{17}$ the new programmes encouraging these policy changes were not fully in place during the first 2 years following passage of Proposition 99, so they could not account for the observed effects. Perhaps the "easier" smokers have been 
reached and one would expect decelerating reductions in smoking as prevalence falls, because the remaining smokers are more strongly addicted.

There are several limitations in this study. Most importantly, not enough time has passed to collect enough data to determine the detailed demand function for tobacco. The effects of price change (due to both the tax increase and industry pre-tax price increases), the various components of the anti-tobacco campaign, and changes in pro-smoking campaigns (ie, cigarette advertising) were not explicitly modelled. There was an increase in the Federal excise tax on tobacco in 1983, within the period used to establish the baseline historical trends which began in 1981; this tax increase slightly "dilutes" the effects obseryed over this baseline period. Repeating the analysis beginning in $1983 \mathrm{had}$ no effect on the qualitative results, because the tax increase was small compared to the overall price increases that occurred since 1981. In addition to responding politically to reduce funding for the Proposition 99 tobacco control campaign, ${ }^{18}$ the industry has modified its marketing and advertising strategies. For example, at the same time that the tobacco industry has been reducing traditional print advertising in most of the country, advertising increased by $50 \%$ in California. ${ }^{19}$

The suspension of the media campaign and the disruption of the remainder of the health education campaign in 1991 and 1992, and their subsequent reinstatement, may provide a natural experiment that permits more detailed analysis of the relative roles of the price and educational components of the decline in tobacco consumption in California following Proposition 99. The fact that tobacco consumption declined faster in California than in the rest of the US following Proposition 99, despite similar price increases nationally and more intensive pro-tobacco advertising in California, suggests that the Proposition 99 health education campaign had an effect on consumption.

\section{Note added in proof:}

Total cigarette consumption in California in fiscal year 1993 was 1.96 billion packs, down from 2.05 billion in 1992. The cumulative effect of Proposition 99 on cigarette consumption up to 30 June 1993 was 1.11 billion packs of cigarettes not sold, worth over $\$ 1.6$ billion in pre-tax sales and $\$ 415$ million in profits to the tobacco companies.

This work was presented in abstract form at the American Heart Association meeting Behavioral Change and Compliance: Keys to Improving Health, Monterey, California, USA, 15-17 January 1993.

This study was supported by funds provided by the Cigarette This study was supported by funds provided by the Cigarette
and Tobacco Tax Surtax Fund of the State of California and Tobacco Tax Surtax Fund of the State of California
through the Tobacco-Related Disease Research Program of the through the Tobacco-Related Disease Research
University of California under award 1RT520.

1 California Revenue and Taxation Code, division 2, part 3, chapter 2, article 2, 30121-30130.

2 Keeler TE, Hu T, Barnett PG. Taxation, regulation, and addiction: a demand function for cigarettes based on time series evidence. University of California, Berkeley: Department of Economics, July 1991. Working paper No 91-173.

3 Flewelling RL, Kenney E, Elder JP, Pierce JP, Johnson M, Bal D. First-year impact of the 1989 California cigarette tax increase on cigarette consumption. Am f Public tax increase on cigarette

4 Burns D, Pierce JP. Tobacco use in California 1990-1991. Sacramento California: California Department of Health Services, 1992

5 Hu T, Bai J, Keeler TE, Barnett PG. The impact of 1989 California major anti-smoking legislation on cigarette consumption: three years later. University of California, Berkeley: Department of Economics, September 1992. Working Paper 92-203.

6 Pierce JP, Farkas A, Evans N, Berry C, Choi W, Rosbrook $\mathrm{B}$, et al. Tobacco use in California 1992. A focus on palifornia Department of Health Services, 1993.

7 The tax burden on tobacco, vol 27. Washington, DC: Tobacco Institute, 1992.

8 Glantz A, Slinker B. Primer of applied regression and analysis of variance. New York: McGraw-Hill, 1990

9 Nowell P. Smokeout-tobacco profits. Associated Press. November, 1992.

10 Sweanor D, Ballin S, Corcoran RD, Davis A, Deasy K, Ferrence RG, et al. Report of the Tobacco Policy Research Study Group on tobacco pricing and taxation in the United States. Tobacco Control 1992; 1: (suppl) S31-S36.

11 Laugesen $M$, Meads C. Advertising, price, income and publicity effects on weekly cigarette sales in New Zealand supermarkets. $B r \mathcal{F}$ Addict 1991; 86: 83-9.

12 Warner $K$. Cigarette advertising and media coverage of smoking and health. $N$ Engl $\mathcal{F}$ Med $1985 ; 312: 384-8$.

13 Schneider L, Klein B, Murphy K. Governmental regulation of cigarette health information. F Law Econ $1981 ; 24$ : of cigarette

14 Skolnick A. Court orders California governor to restore anti-smoking media campaign. $\mathcal{F} A M A$ 1992; 267: 2721-2.

15 Skolnick A. American Heart Association seeks to delay state health department director's confirmation. $\mathcal{F} A M A 1992$; 267: 2722-4

16 Wasserman J, Manning W, Newhouse J, Winkler J. The effects of excise taxes and regulations on cigarette smoking. F Health Econ $1991 ; 10 ; 43-64$.

17 Woodruff T, Rosbrook B, Pierce J, Glantz S. Lower levels of cigarette consumption found in smoke-free workplaces in California. Arch Intern Med 1993; 153: 1485-93.

18 Begay ME, Traynor M, Glantz SA. The tobacco industry, state politics, and tobacco education in California. $A m \mathcal{F}$ Public Health 1993; 83: 1214-21.

19 Johnson CA, Sanford D. Tobacco industry response evaluation. In: Independent evaluation of efforts to prevent and control tobacco use in California. JP Elder, E Kenney, eds. San Diego: CSUSD, 1991. 